\title{
A NOTE ON CONTROLLABILITY OF NEUTRAL VOLTERRA INTEGRODIFFERENTIAL SYSTEMS ${ }^{1}$
}

\author{
K. BALACHANDRAN and P. BALASUBRAMANIAM \\ Bharathiar University \\ Department of Mathematics \\ Coimbatore 641046 \\ Tamil Nadu, INDIA
}

\begin{abstract}
Sufficient conditions for the controllability of nonlinear neutral Volterra integrodifferential systems are established. The results are obtained using the Schauder fixed point theorem.
\end{abstract} point method.

Key words: Controllability, neutral Volterra systems, fixed AMS (MOS) subject classifications: $\quad$ 93B05.

\section{INTRODUCTION}

The theory of functional differential equations has been studied by several authors $[6$, $9,11,15]$. The problem of controllability of linear neutral systems has been investigated by Banks and Kent [3], and Jacobs and Langenhop [12]. Motivation for physical control systems and its importance in other fields can be found in [11, 13]. Angell [1] and Chukwu [4] discussed the functional controllability of nonlinear neutral systems, and Underwood and Chukwu [16] studied the null controllability for such systems. Further, Chukwu [5] considered the Euclidian controllability of a neutral system with nonlinear base. Onwuatu [14] discussed the problem for nonlinear systems of neutral functional differential equations with limited controls. Gahl [10] derived a set of sufficient conditions for the controllability of nonlinear neutral systems through the fixed point method developed by Dauer [7]. Recently, Balachandran [2] established sufficient conditions for the controllability of nonlinear neutral Volterra integrodifferential systems and infinite delay neutral Volterra systems. In this paper we shall derive a new set of sufficient conditions for the controllability of nonlinear neutral Volterra integrodifferential systems by suitably adopting the technique of Do [8].

\footnotetext{
${ }^{1}$ Received: November, 1991. Revised: March, 1993.
} 


\section{PRELIMINARIES}

Let $J=\left[0, t_{1}\right], t_{1}>0$ and let $Q$ be the Banach space of all continuous functions

$$
(x, u): J \times J \rightarrow R^{n} \times R^{m}
$$

with the norm defined by

$$
\|(x, u)\|=\|x\|+\|u\|
$$

where $\|x\|=\sup _{t \in J}|x(t)|$. Define the norm of a continuous $n \times m$ matrix valued function $D: J \rightarrow R^{n} \times R^{m}$ by

where $d_{i j}$ are the elements of $D$.

$$
\|D(t)\|=\max _{i} \sum_{j=1}^{m} \max _{t \in J}\left|d_{i j}(t)\right|
$$

Consider the linear neutral Volterra integrodifferential system of the form

$$
\frac{d}{d t}\left[x(t)-\int_{0}^{t} C(t-s) x(s) d s-g(t)\right]=A x(t)+\int_{0}^{t} G(t-s) x(s) d s+B(t) u(t)
$$

and the nonlinear system

$$
\begin{gathered}
\frac{d}{d t}\left[x(t)-\int_{0}^{t} C(t-s) x(s) d s-g(t)\right] \\
=A x(t)+\int_{0}^{t} G(t-s) x(s) d s+B(t) u(t)+f(t, x(t), u(t)),
\end{gathered}
$$

where $x(t) \in R^{n}, u(t) \in R^{m}, C(t)$ and $G(t)$ are $n \times n$ continuous matrix valued functions and $B(t)$ is a continuous $n \times m$ matrix valued functions, $A$ a constant $n \times n$ matrix and $f$ and $g$ are, respectively, continuous and absolutely continuous vector functions. We consider the controllability on a bounded interval $J$ of system (2).

Definition 1 [18]: A function $x: J \rightarrow R^{n}$ is said to be a solution of the initial value problem (1) or (2) through $(0, x(0))$ on $J$, if

(i) $x$ is continuous on $J$,

(ii) $\left[x(t)-\int_{0}^{t} C(t-s) x(s) d s-g(t)\right]$ is absolutely continuous on $J$,

(iii) (1) or (2) holds almost everywhere on $J$.

Definition 2: The system (2) is said to be controllable on $J$ if for every $x(0)$, $x_{1} \in R^{n}$ there exists a control function $u(t)$ defined on $J$ such that the solution of (2) satisfies 
$x\left(t_{1}\right)=x_{1}$

The solution of (1) can be written, as in [17], in the form

$$
x(t)=Z(t)[x(0)-g(0)]+g(t)+\int_{0}^{t} \dot{Z}(t-s) g(s) d s+\int_{0}^{t} Z(t-s) B(s) u(s) d s,
$$

where $\dot{Z}(t-s)=\frac{\partial Z}{\partial t}(t-s)$ and $Z(t)$ is an $n \times n$ continuously differentiable matrix satisfying the equation

$$
\frac{d}{d t}\left[Z(t)-\int_{0}^{t} C(t-s) Z(s) d s\right]=A Z(t)-\int_{0}^{t} G(t-s) Z(s) d s
$$

with $Z(0)=I$ and the solution of nonlinear system (2) is given by

$$
\begin{aligned}
x(t) & =Z(t)[x(0)-g(0)\}+g(t)+\int_{0}^{t} \dot{Z}(t-s) g(s) d s \\
& +\int_{0}^{t} Z(t, s)[B(s) u(s)+f(s, x(s), u(s))] d s .
\end{aligned}
$$

Define the matrix $W$ by

$$
W(t)=\int_{0}^{t} Z(t-s) B(s) B^{*}(s) Z^{*}(t-s) d s
$$

where the $*$ denotes the transpose matrix. We know that system (1) is controllable on $J$ if and only if $W$ is nonsingular [2].

It is clear that $x_{1}$ can be obtained if there exist continuous functions $x(\cdot)$ and $u(\cdot)$ such that

$$
\begin{aligned}
u(t) & =B^{*}(t) Z^{*}\left(t_{1}-t\right) W^{-1}\left(t_{1}\right)\left[x_{1}-Z\left(t_{1}\right)(x(0)-g(0))-g\left(t_{1}\right)\right. \\
& \left.-\int_{0}^{t_{1}} \dot{Z}\left(t_{1}-s\right) g(s) d s-\int_{0}^{t_{1}} Z\left(t_{1}-s\right) f(s, x(s), u(s)) d s\right]
\end{aligned}
$$

and

$$
\begin{aligned}
x(t) & =Z(t)[x(0)-g(0)]+g(t)+\int_{0}^{t} \dot{Z}(t-s) g(s) d s \\
& +\int_{0}^{t} Z(t-s)[B(s) u(s)+f(s, x(s), u(s))] d s .
\end{aligned}
$$

Now, we will find conditions for the existence of such $x()$ and $u()$. If $\alpha_{i} \in L^{1}(J)$ $(i=1,2, \ldots, q)$ then $\left\|\alpha_{i}\right\|(i=1,2, \ldots, q)$ is the $L^{1}$ norm of $\alpha_{i}(s) \quad(i=1,2, \ldots, q)$. That is, 


$$
\left\|\alpha_{i}\right\|=\int_{0}^{t_{1}}\left|\alpha_{i}(s)\right| d s \quad(i=1,2, \ldots, q) .
$$

Next, for our convenience, let us introduce the following notations:

$$
\begin{aligned}
& K=\max \left\{\|Z(t-s)\|: 0 \leq s \leq t \leq t_{1}\right\}, \\
& k=\max \left\{\|Z(t-s) B(s)\| t_{1}, 1\right\}, \\
& a_{1}=3 k\left\{\left\|B^{*}(s) Z^{*}\left(t_{1}-s\right)\right\|\left\|W^{-1}\left(t_{1}\right)\right\|\left\|Z\left(t_{1}-s\right)\right\|\left\|\alpha_{i}\right\|\right\}, \quad(i=1,2, \ldots, q) \\
& b_{i}=3 K\left\|\alpha_{i}\right\|, \quad(i=1,2, \ldots, q) \\
& c_{i}=\max \left\{a_{i}, b_{i}\right\}, \quad(i=1,2, \ldots, q) \\
& d_{1}=3 k\left\|B^{*}(s) Z^{*}\left(t_{1}-s\right)\right\|\left\|W^{-1}\left(t_{1}\right)\right\|\left[\left|x_{1}\right|+\left\|Z\left(t_{1}\right)\right\||x(0)-g(0)|\right. \\
& d_{2}=3\left\|Z\left(t_{1}\right)\right\||x(0)-g(0)|+\left|g\left(t_{1}\right)\right|+\left|\int_{0} \dot{Z}\left(t_{1}-s\right) g(s) d s\right|, \\
& d=\max \left\{d_{1}, d_{2}\right\} .
\end{aligned}
$$

\section{MAIN RESULTS}

Now, we will prove the following main theorem, which is a generalization of Theorem 2 of Balachandran [2].

Theorem: Let measurable functions $\phi_{i}: R^{n} \times R^{m} \rightarrow R^{+} \quad(i=1,2, \ldots, q)$ and $L^{1}$ functions $\alpha_{i}: J \rightarrow R^{+} \quad(i=1,2, \ldots, q)$ be such that

$$
|f(t, x, u)| \leq \sum_{i=1}^{q} \alpha_{i}(t) \phi_{i}(x, u) \text { for every }(t, x, u) \in J \times R^{n} \times R^{m} .
$$

Then the controllability of (1) implies the controllability of (2) if

$$
\lim _{r \rightarrow \infty} \sup \left(r-\sum_{i=1}^{q} c_{i} \sup \left\{\phi_{i}(x, u):\|(x, u)\| \leq r\right\}\right)=\infty .
$$

Proof: Define $T: Q \rightarrow Q$ by

$$
T(x, u)=(y, v)
$$

where

$$
v(t)=B^{*}(t) Z^{*}\left(t_{1}-t\right) W^{-1}\left(t_{1}\right)\left[x_{1}-Z\left(t_{1}\right)(x(0)-g(0))-g\left(t_{1}\right)\right.
$$


and

$$
\left.-\int_{0}^{t_{1}} \dot{Z}\left(t_{1}-s\right) g(s) d s-\int_{0}^{t_{1}} Z\left(t_{1}-s\right) f(s, x(s), u(s)) d s\right]
$$

$$
\begin{aligned}
y(t) & =Z(t)[x(0)-g(0)]+g(t)+\int_{0}^{t} \dot{Z}(t-s) g(s) d s \\
& +\int_{0}^{t} Z(t-s)[B(s) v(s)+f(s, x(s), u(s))] d s .
\end{aligned}
$$

Based on our assumptions, $T$ is continuous. Clearly the solutions $u(\cdot)$ and $x(\cdot)$ to (3) and (4) are fixed points of $T$. We will prove the existence of such fixed points by using the Schauder fixed point theorem.

Let $\psi_{i}(r)=\sup \left\{\phi_{i}(x, u):\|(x, u)\| \leq r\right\}$. Since (5) holds, there exists $r_{0}>0$ such that

Now, let

$$
\sum_{i=1}^{q} c_{i} \psi_{i}\left(r_{0}\right)+d \leq r_{0}
$$

$$
Q_{r_{0}}=\left\{(x, u) \in Q:\|(x, u)\| \leq r_{0}\right\} .
$$

If $(x, u) \in Q_{r_{0}}$, from (6) and (7), we have

$$
\begin{gathered}
\|v\| \leq\left\|B^{*}(t) Z^{*}\left(t_{1}-t\right)\right\|\left\|W^{-1}\left(t_{1}\right)\right\|\left[\left|x_{1}\right|+\left\|Z\left(t_{1}\right)\right\||x(0)-g(0)|\right. \\
\left.+\left|g\left(t_{1}\right)\right|+\left|\int_{0}^{t_{1}} \dot{Z}\left(t_{1}-s\right) g(s) d s\right|+\int_{0}^{t_{1}}\left\|Z\left(t_{1}-s\right)\right\| \sum_{i=1}^{q} \alpha_{i}(s) \phi_{i}(x(s), u(s)) d s\right] \\
\leq\left(d_{1} / 3 k\right)+(1 / 3 k) \sum_{i=1}^{q} a_{i} \psi_{i}\left(r_{0}\right) \\
\leq(1 / 3 k)\left(d+\sum_{i=1}^{q} c_{i} \psi_{i}\left(r_{0}\right)\right) \\
\leq\left(r_{0} / 3 k\right) \leq\left(r_{0} / 3\right)
\end{gathered}
$$

and

$$
\begin{gathered}
\|y\| \leq\|Z(t)\||x(0)-g(0)|+|g(t)|+\left|\int_{0}^{t} \dot{Z}(t-s) g(s) d s\right| \\
+\int_{0}^{t}\|Z(t-s) B(s)\|\|v\| d s+\int_{0}^{t}\|Z(t, s)\| \sum_{i=1}^{q} \alpha_{i}(s) \phi_{i}(x(s), u(s)) d s \\
\leq(d / 3)+k\|v\|+K \sum_{i=1}^{q}\left\|\alpha_{i}\right\| \psi_{i}\left(r_{0}\right)
\end{gathered}
$$




$$
\begin{gathered}
\leq(d / 3)+k\|v\|+(1 / 3) \sum_{i=1}^{q} c_{i} \psi_{i}\left(r_{0}\right) \\
\leq(1 / 3)\left(d+\sum_{i=1}^{q} c_{i} \psi_{i}\left(r_{0}\right)\right)+k\|v\| \\
\leq\left(r_{0} / 3\right)+\left(r_{0} / 3\right)=2\left(r_{0} / 3\right) .
\end{gathered}
$$

Hence $T$ maps $Q_{r_{0}}$ into itself. Further, it is easy to see that $T\left(Q_{r}\right)$ is equicontinuous for all $r>0$ [8]. By the Ascoli-Arzela theorem, $\overline{T\left(Q_{r_{0}}\right)}$ is compact in $Q$. Since $Q_{r_{0}}$ is nonempty, closed, bounded and convex, by the Schauder fixed point theorem, solutions of (3) and (4) exist. Hence the proof is complete.

To apply the above theorem we have to construct $\alpha_{i}$ 's and $\phi_{i}$ 's such that (5) is satisfied. These constructions are different for different situations. However, an obvious construction of $\alpha_{i}$ 's and $\phi_{i}$ 's is easily achieved by taking $q=1, \alpha_{1}=\alpha=1$ and

$$
\phi_{1}(x, u)=\phi(x, u)=\sup \{|f(t, x, u)|: t \in J\} .
$$

In this case (5) holds if

$$
\lim _{r \rightarrow \infty} \inf (1 / r) \sup \{\phi(x, u):\|(x, u)\| \leq r\}<1 / c_{1}
$$

Now, we will state a corollary which is a particular case of the above theorem and it was proved by Balachandran [2].

Corollary: If the continuous function $f$ satisfies the condition

$$
\lim _{\|(x, u)\| \rightarrow \infty} \frac{|f(t, x, u)|}{\|(x, u)\|}=0
$$

uniformly in $t \in J$ and if system (1) is controllable on $J$, then system (2) is controllable on $J$.

\section{REFERENCES}

[1] Angell, T.S., On controllability for nonlinear hereditary systems: A fixed point approach, Nonlinear Analysis: Theory, Methods and Applications 4 (1980), 529-548.

[2] Balachandran, K., Controllability of neutral Volterra integrodifferential systems, J. of Australian Math. Soc., Ser. B, 34 (1992), 18-25.

[3] Banks, H.T. and G.A. Kent, Control of functional differential equations of retarded and neutral type to target sets in function space. SIAM J. on Control 10, (1972), 562-593. 
[4] Chukwu, E.N., Functional inclusion and controllability of nonlinear neutral functional differential systems, J. of Optim. Theory and Appl. 29 (1979), 291-300.

[5] Chukwu, E.N., On the Euclidian controllability of a neutral system with nonlinear base, Nonlinear Analysis: Theory, Methods and Applications 11 (1987), 115-123.

[6] Chukwu, E.N. and H.C. Simpson, Perturbations on nonlinear systems of neutral type, J. of Diff. Equations 82 (1989), 28-59.

[7] Dauer, J.P., Nonlinear perturbations of quasilinear control systems, J. of Math. Anal. and Appl. 54 (1976), 717-725.

[8] Do, V.N., Controllability of semilinear systems, J. of Optim. Theory and Appl. 65 (1990), 41-52.

[9] Fuchs, E., The degeneracy property in linear autonomous functional differential equations of neutral type, J. of Math. Anal. and Appl. 90 (1983), 527-549.

[10] Gahl, R.D., Controllability of nonlinear systems of neutral type, J. of Math. Anal. and Appl. 63 (1978), 33-42.

[11] Hale, J.K., Theory of Functional Differential Equations, Springer Verlag, New York 1977 .

[12] Jacobs, M.Q. and C.E. Langenhop, Criteria for function space controllability of linear neutral systems, SIAM J. on Control and Optim. 14 (1976), 1009-1048.

[13] O'Conner, D.A., State Controllability and Observability for Linear Neutral Systems, Washington University, D.Sc. Thesis 1978.

[14] Onwuatu, J.U., On the null controllability in function space of nonlinear systems of neutral functional differential equations with limited controls, J. of Optim. Theory and Appl. 42 (1984), 397-420.

[15] Tadmore, G., Functional differential equations of retarded and neutral type: analytic solutions and piecewise continuous controls, J. of Diff. Equations 51 (1984), 151-181.

[16] Underwood, R.G. and E.N. Chukwu, Null controllability of nonlinear neutral differential equations, J. of Math. Anal. and Appl. 129 (1988), 326-345.

[17] Wu, J., Globally stable periodic solutions of linear neutral Volterra integrodifferential equations, J. of Math. Anal. and Appl. 130 (1988), 474-483.

[18] Wu, J., Unified treatment of local theory of NFDES with infinite delay, Tamkang J. of Math. 22 (1991), 51-72. 


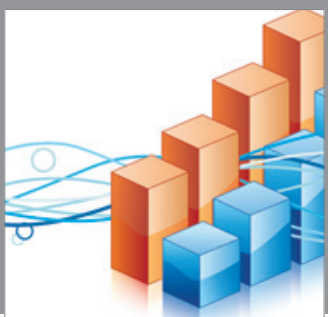

Advances in

Operations Research

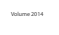

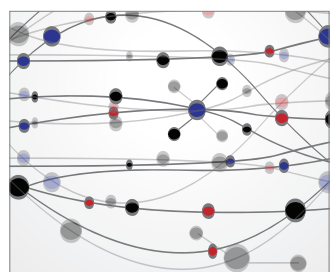

\section{The Scientific} World Journal
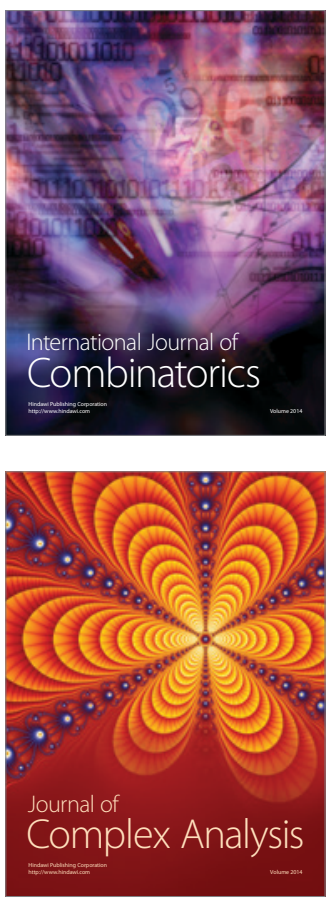

International Journal of

Mathematics and

Mathematical

Sciences
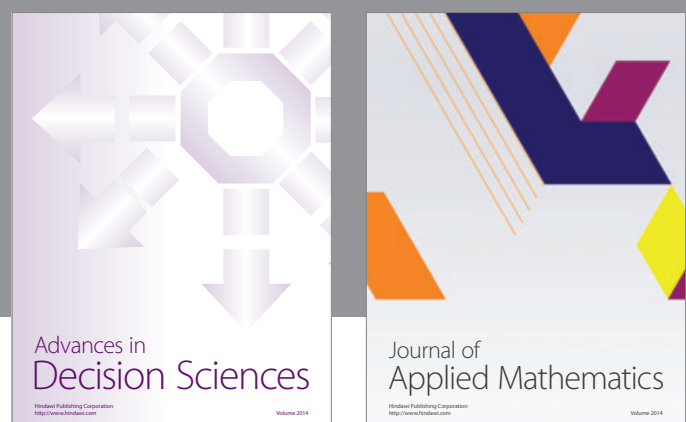

Journal of

Applied Mathematics
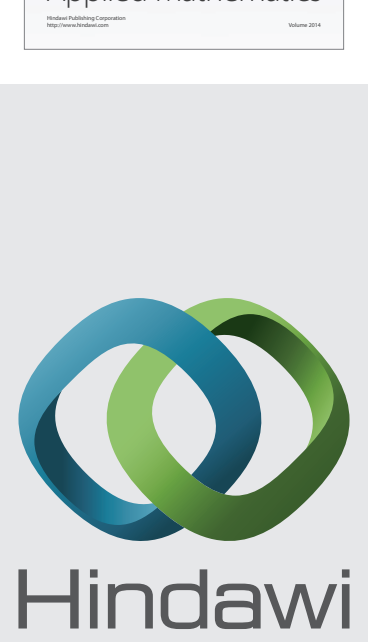

Submit your manuscripts at http://www.hindawi.com
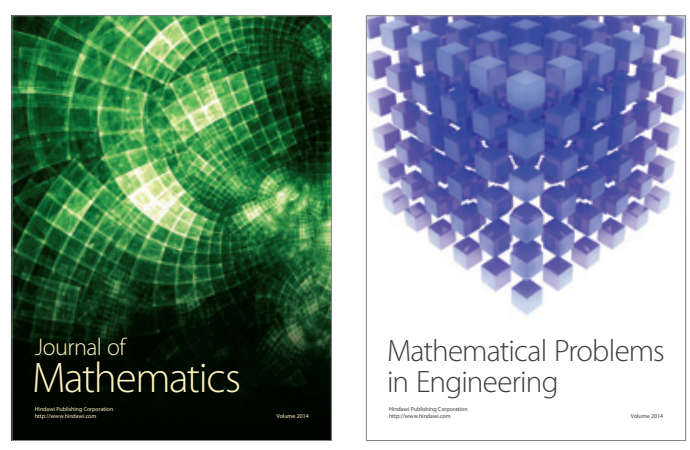

Mathematical Problems in Engineering
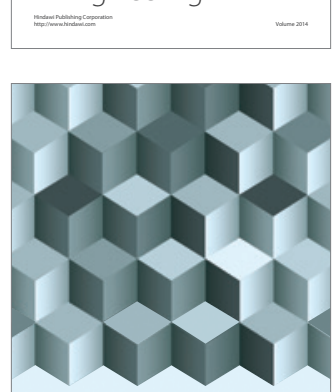

Journal of

Function Spaces
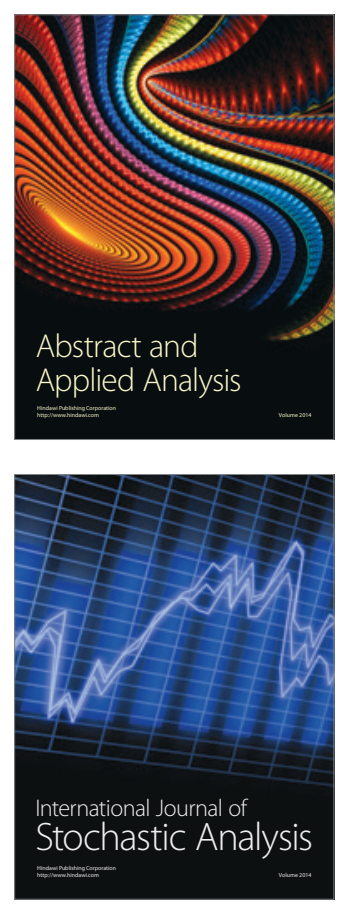

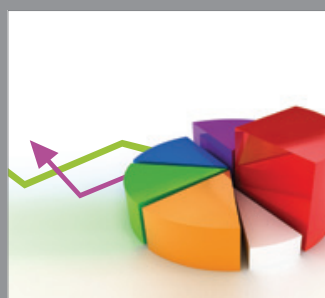

ournal of

Probability and Statistics

Promensencen
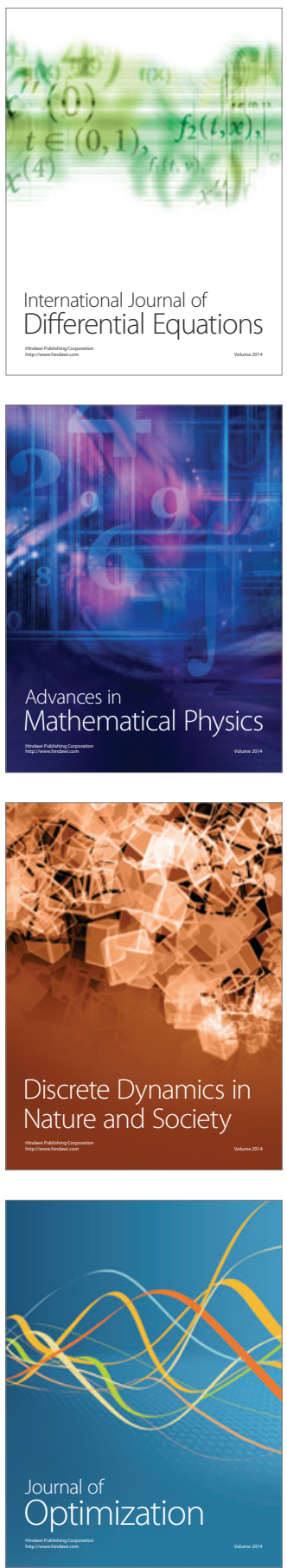